\title{
AVALIAÇÃo DE DIFERENTES TIPOS DE CARVÃo ATIVO NA DESTOXIFICAÇÃo DE HIDROLISADO DE PALHA DE ARROZ PARA PRODUÇÃO DE XILITOL ${ }^{1}$
}

\author{
Solange Inês MUSSATTO², Inês Conceição ROBERTO2,*
}

\begin{abstract}
RESUMO
O hidrolisado hemicelulósico de palha de arroz foi tratado com cinco tipos de carvão ativo (pó e granulado) com o objetivo de remover, por adsorção, compostos tóxicos que podem agir como inibidores no processo de bioconversão de xilose em xilitol, por Candida guilliermondii. Os valores máximos de fator de rendimento em xilitol $\left(\mathrm{Y}_{\mathrm{P} / \mathrm{S}}=0,67 \mathrm{~g} \mathrm{~g}^{-1}\right)$ e produtividade volumétrica $\left(\mathrm{Q}_{\mathrm{p}}=0,61 \mathrm{~g} \mathrm{~L}^{-1} \mathrm{~h}^{-1}\right)$ foram atingidos quando o hidrolisado foi tratado com carvão ativo em pó de partículas de tamanho pequeno $(0,043 \mathrm{~mm})$, baixa granulometria (32\% retidos em peneira de 325 mesh) e grande área superficial $\left(860 \mathrm{~m}^{2} \mathrm{~g}^{-1}\right)$, características as quais favoreceram a adsorção dos compostos tóxicos.

Palavras-chave: carvão ativo; adsorção; palha de arroz; hidrolisado hemicelulósico; xilitol.
\end{abstract}

\section{SUMMARY}

EVALUATION OF DIFFERENT KINDS OF ACTIVATED CHARCOAL USED FOR RICE STRAW HYDROLYSATE DETOXIFICATION FOR XYLITOL PRODUCTION. Rice straw hemicellulosic hydrolysate was treated with five kinds of activated charcoal (powdered and granulated) in order to remove, by adsorption, toxic compounds that can be act as inhibitors in the bioconversion of xylose to xylitol, by Candida guilliermondii. Maximum values of xylitol yield factor $\left(\mathrm{Y}_{\mathrm{P} / \mathrm{s}}=0.67 \mathrm{~g} \mathrm{~g}^{-1}\right)$ and volumetric productivity $\left(\mathrm{Q}_{\mathrm{p}}=0.61 \mathrm{~g} \mathrm{~L}^{-1} \mathrm{~h}^{-1}\right)$ were provided by powdered activated charcoal with small particles size $(0.043 \mathrm{~mm})$, low granulometry $(32 \%$ restrained in $325 \mathrm{mesh})$ and large surface area $\left(860 \mathrm{~m}^{2} \mathrm{~g}^{-1}\right)$, characteristics which favoured the toxic compounds adsorption.

Keywords: activated charcoal; adsorption; rice straw; hemicellulosic hydrolysate; xylitol.

\section{1 - INTRODUÇÃO}

O arroz é um dos alimentos mais consumidos não só no Brasil como em quase todos os países do mundo. No Brasil, segundo dados do IBGE, a produção de arroz com casca na safra de 2001 foi de aproximadamente 11,1 milhões de toneladas, quantidade suficiente para gerar cerca de 15 milhões de toneladas de palha de arroz. A palha de arroz apresenta como principais constituintes orgânicos a celulose, a hemicelulose e a lignina. A xilose, açúcar predominante da fração hemicelulósica, pode ser convertida por fermentação em diferentes produtos, dentre os quais o xilitol tem se tornado uma opção atrativa devido as suas propriedades de poder adoçante e anticariogenicidade [20], além de prevenir otites médias agudas [28] e a osteoporose [11].

A bioconversão de xilose em xilitol, utilizando os hidrolisados oriundos da fração hemicelulósica dos materiais lignocelulósicos é dependente não apenas da capacidade produtiva do microrganismo, mas também de sua tolerância a efeitos inibitórios causados por diversos compostos tóxicos presentes nestes hidrolisados [5]. Tais compostos tóxicos podem ser divididos em quatro grupos: (a) produtos de degradação dos açúcares incluindo o furfural e o hidroximetilfurfural; (b) produtos de degradação da lignina (PDL), incluindo uma variedade de compostos aromáticos; (c) substâncias li-

\footnotetext{
1. Recebido para publicação em 22/11/2002. Aceito para publicação em 18/09/2003 (001008).

2. Departamento de Biotecnologia, Faculdade de Engenharia Química de Lorena-FAENQUIL. Rodovia Itajubá-Lorena, Km 74,5, CEP 12600-970 Lorena-SP. E-mail: ines@debiq.faenquil.br

*A quem a correspondência deve ser enviada.
}

beradas da estrutura lignocelulósica durante o processo hidrolítico, como ácido acético e extrativos da madeira (resinas ácidas, ácidos tanínicos e terpenos); (d) metais provenientes da corrosão dos equipamentos de hidrólise, em particular os íons ferro, cromo, níquel e cobre [16]. Devido à presença destes compostos tóxicos, quando o hidrolisado hemicelulósico é utilizado diretamente em processos de bioconversão (sem serem submetidos a um tratamento prévio de destoxificação), ocorre diminuição na eficiência do processo fermentativo que atinge baixos rendimentos e produtividades. Além disso, reações de oxidação destes compostos, as quais ocorrem durante a neutralização dos hidrolisados, resultam na formação de pigmentos de cor marrom-escura, os quais diminuem a qualidade dos alimentos processados [27].

Para contornar os problemas de toxicidade dos hidrolisados, vários procedimentos têm sido utilizados incluindo a precipitação de impurezas com a variação de pH [21], adsorção em carvão ativo [18], resinas de troca iônica [10], entre outros. Dentre estes procedimentos, destaca-se o uso de carvão ativo, que vem sendo amplamente utilizado em processos de destoxificação para produção de xilitol $[1,7,18]$.

De acordo com vários autores, os carvões ativos têm se mostrado altamente eficientes na remoção de compostos que transmitem cor e odor [3,30], e na remoção de metais e compostos orgânicos de baixa massa molar [19]. Desta forma, os carvões ativos têm sido usados em tratamentos como, purificação, desintoxicação, desodorização, filtração, descoloração, declorificação, remoção ou modificação de sabor e concentração de uma infinidade de materiais e substâncias líquidos e gasosos [6]. Essas aplicações fazem do car- 
vão ativo, um produto de grande interesse para muitos setores econômicos em diversas áreas, como: alimentícia, farmacêutica, química, petrolífera, nuclear, automobilística, mineração, no tratamento de água potável, água industrial e do ar atmosférico, podendo ser utilizado tanto na forma de carvão granulado, como em pó.

A capacidade do carvão ativo em adsorver compostos é dependente de vários fatores, como: o processo de ativação a que o carvão foi submetido, granulometria, área superficial, densidade, $\mathrm{pH}$, teor de cinzas, estrutura interna dos poros, presença de grupos funcionais na superfície dos poros que conferem alta reatividade da superfície, dimensões dos poros e alta resistência mecânica $[2,3,6]$.

No presente trabalho, avaliou-se o tratamento do hidrolisado hemicelulósico de palha de arroz com diferentes tipos de carvão ativo, com o objetivo de remover do hidrolisado compostos tóxicos ao metabolismo microbiano, e conseqüentemente melhorar os resultados da bioconversão de xilose a xilitol pela levedura Candida guilliermondii.

\section{2 - MATERIAIS E MÉTODOS}

\section{1 - Obtenção e concentração do hidrolisado}

Após o recebimento, a palha de arroz foi seca ao sol e cominuída em moinho tipo martelo a um tamanho de aproximadamente $1 \mathrm{~cm}$ de comprimento por $1 \mathrm{~mm}$ de espessura. O hidrolisado hemicelulósico foi obtido por catálise ácida em reator confeccionado em aço inox AISI 316 com capacidade de 350 litros, munido de aquecimento indireto por resistência elétrica por camisa de óleo térmico. As reações foram realizadas com $\mathrm{H}_{2} \mathrm{SO}_{4}$ na concentração de $100 \mathrm{mg}$ de ácido por grama de matéria seca a $120^{\circ} \mathrm{C}$ por $20 \mathrm{~min}$, mantendo relação sólido:líquido de 1:10. Visando aumentar a concentração de xilose no hidrolisado nove vezes maior que a inicial, este foi concentrado sob pressão reduzida em evaporador, com capacidade de 4 litros a uma temperatura de aproximadamente $70^{\circ} \mathrm{C}$. Os hidrolisados original e concentrado foram caracterizados quanto ao $\mathrm{pH}$, à concentração dos açúcares: xilose, glicose e arabinose, e quanto à concentração de compostos provenientes da degradação dos açúcares: furfural e hidroximetilfurfural.

\section{2 - Tratamento do hidrolisado}

O tratamento do hidrolisado baseou-se na alteração do $\mathrm{pH}$ original $(0,4)$ para 8,0 , pela adição de $\mathrm{NaOH}$ (pastilhas), seguido de sua redução para o $\mathrm{pH}$ inicial de fermentação $(6,5)$ pela adição de $\mathrm{H}_{2} \mathrm{SO}_{4}(72 \%$ p/p). Após cada alteração de $\mathrm{pH}$, o precipitado foi removido por centrifugação a $2000 \mathrm{~g}$ por $30 \mathrm{~min}$. Ao hidrolisado foi então adicionado carvão ativo na proporção de $1 \mathrm{~g}$ de carvão para $40 \mathrm{~g}$ de hidrolisado, com posterior agitação em incubadora de movimento giratório a $200 \mathrm{rpm} \mathrm{e} 30^{\circ} \mathrm{C}$ por 1h. Após este tempo, o hidrolisado foi centrifugado a 2000 g por 30min, para remoção de sólidos. O hidrolisado tratado foi caracterizado quanto à concentração dos açúcares: xilose, glicose e arabinose; quanto à concentração de compostos provenientes da degradação dos açúcares: furfural e hidroximetilfurfural; e quanto ao teor de compostos derivados de lignina (PDL).

\section{3 - Processo fermentativo}

O microrganismo utilizado foi a levedura Candida guilliermondii FTI 20037, selecionada para produção de xilitol [4]. A cultura foi mantida repicada em tubos de ensaio contendo ágar malte inclinado e conservada em geladeira a $4^{\circ} \mathrm{C}$ para posterior preparo do inóculo. Todos os inóculos foram preparados transferindo-se uma alçada de células proveniente do repique em meio de manutenção, para tubos de ensaio contendo água destilada esterilizada. Alíquotas de $1 \mathrm{~mL}$ desta suspensão foram transferidas para frascos Erlenmeyer de $125 \mathrm{~mL}$ contendo $50 \mathrm{~mL}$ de meio composto por ( $\left.\mathrm{g} \mathrm{L}^{-1}\right)$ : xilose: 20,0; sulfato de amônio: 3,0; cloreto de cálcio dihidratado: 0,10; e extrato de farelo de arroz: 20,0. Os frascos inoculados foram incubados a $30^{\circ} \mathrm{C}$ em agitador rotatório tipo "shaker", a 200rpm por 24h. Após este tempo, as células foram separadas por centrifugação a $2000 \mathrm{~g}$ por 20min e ressuspensas em água destilada esterilizada de forma a se obter uma suspensão celular densa. A partir desta suspensão foi calculado o volume necessário para fornecer concentração celular inicial de $3,0 \mathrm{~g} \mathrm{~L}^{-1}$ no meio de fermentação. As soluções de todos os componentes foram preparadas separadamente e esterilizadas a $121^{\circ} \mathrm{C}$ por 20 min, exceto a solução de xilose que foi autoclavada a $112^{\circ} \mathrm{C}$ por $15 \mathrm{~min}$. $\mathrm{O}$ meio de fermentação foi preparado com o hidrolisado tratado e diluído com água esterilizada de forma a se obter concentração inicial de xilose de $90 \mathrm{~g} \mathrm{~L}^{-1}$. Os experimentos foram conduzidos em frascos Erlenmeyer de $125 \mathrm{~mL}$ contendo $50 \mathrm{~mL}$ do meio de fermentação e incubados a $30^{\circ} \mathrm{C}$ sob agitação de 250rpm.

\section{4 - Acompanhamento analítico dos experimen- tos}

O acompanhamento das fermentações foi realizado retirando-se amostras para verificação do teor de açúcares (glicose, xilose, arabinose e xilitol), determinação da concentração celular e do $\mathrm{pH}$. O crescimento celular foi acompanhado por medida das absorbâncias a 600nm em espectrofotômetro, sendo as amostras devidamente diluídas para a faixa de leitura entre 0,05 a 0,5 unidades de DO (densidade óptica). A concentração celular foi determinada utilizando-se a equação obtida da regressão linear dos dados da curva padrão entre massa seca e absorbância.

As concentrações de glicose, xilose, arabinose e xilitol presentes no hidrolisado foram determinadas por Cromatografia Líquida de Alta Eficiência (CLAE), nas seguintes condições: coluna BIO-RAD Aminex HPX-87H (300 x 7,8mm); temperatura: $45^{\circ} \mathrm{C}$; eluente: ácido sulfúrico $0,01 \mathrm{~N}$; fluxo: $0,6 \mathrm{~mL} \mathrm{~min}^{-1}$; volume de amostra: 20ul; detector: índice de refração. Após a diluição das amostras, estas foram filtradas em filtro Sep Pak C18 (MILLIPORE). O eluente antes de ser utilizado foi fil- 
trado à pressão reduzida e degaseificado em banho de ultra-som por 25 minutos.

As concentrações de furfural e hidroximetilfurfural foram determinadas por CLAE, nas seguintes condições: coluna Waters Resolve $\mathrm{C}_{18} 5 \mu \mathrm{m}$ (3,9 x 300mm); temperatura ambiente; eluente: acetonitrila/água (1/8 com $1 \%$ de ácido acético) degaseificado; fluxo: $0,8 \mathrm{~mL} \mathrm{~min}^{-1}$; volume de amostra: $20 \mu \mathrm{l}$ e detector: UV a $276 \mathrm{~nm}$. As amostras foram previamente diluídas com água bidestilada e filtradas em membranas do tipo HAWP 04700 com poros de $0,45 \mu \mathrm{m}$ (Waters Associates - MILLIPORE). As concentrações destes compostos foram calculadas a partir de curvas de calibração obtidas de soluções padrões. Os produtos derivados de lignina foram estimados através da leitura das absorbâncias a 279nm [17].

\section{3 - RESULTADOS E DISCUSSÃO}

\section{1 - Composição do hidrolisado}

O hidrolisado foi obtido pelo processo de hidrólise ácida, sob condições brandas, visando a recuperação de uma fração hemicelulósica contendo xilose como maior constituinte. O processo de concentração sob pressão reduzida foi empregado para aumentar o teor inicial de xilose no hidrolisado, pois a concentração inicial de substrato é um dos principais fatores que afetam o rendimento de xilitol por leveduras. Os resultados referentes à composição do hidrolisado antes (Hidrolisado Original) e após o processo de concentração (Hidrolisado Concentrado), estão apresentados na Tabela 1.

TABELA 1. Composição parcial de hidrolisado de palha de arroz obtido por hidrólise ácida, em sua forma original e após ser submetido ao processo de concentração.

\begin{tabular}{ccc}
\hline Composto & $\begin{array}{c}\text { Hidrolisado Original } \\
\left(\mathrm{g} \mathrm{L}^{-1}\right)\end{array}$ & $\begin{array}{c}\text { Hidrolisado Concentrado } \\
\left(\mathrm{g} \mathrm{L}^{-1}\right)\end{array}$ \\
\hline Glicose & 3,70 & 34,70 \\
Xilose & 16,40 & 160,90 \\
Arabinose & 2,60 & 27,50 \\
Furfural & 0,09 & 0,06 \\
Hidroximetilfurfural & 0,20 & 0,50 \\
\hline
\end{tabular}

Observa-se que após a etapa de concentração do hidrolisado, os açúcares glicose, xilose e arabinose tiveram aumento proporcional ao fator de concentração, mantendo-se uma relação xilose/glicose da ordem de 4,5. Sendo assim, não houve degradação dos açúcares presentes no hidrolisado durante a etapa de concentração a vácuo. Dentre os produtos da degradação dos açúcares, somente o hidroximetilfurfural (HMF) (produto de degradação de hexoses) teve sua concentração aumentada, porém em nível não proporcional ao fator de concentração utilizado, dado sua volatilidade.

O furfural (produto da degradação de pentoses), por ser um composto volátil, teve sua concentração reduzida a níveis considerados não inibitórios ao metabolismo microbiano $\left(0,06 \mathrm{gL}^{-1}\right)$, após a etapa de concentração
[22,23]. Em relação ao HMF, o hidrolisado concentrado apresentou concentração de cerca de $0,5 \mathrm{~g} \mathrm{~L}^{-1}$ deste composto, que também pode ser considerada não inibitória ao metabolismo do microrganismo. De acordo com vários autores, concentrações acima de $1 \mathrm{~g} \mathrm{~L}^{-1} \mathrm{de} \mathrm{HMF}$, são reportadas como sendo inibitórias ao metabolismo microbiano [8, 23]. TAHERZADEH et al. [26] reportaram que o crescimento de Saccharomyces cerevisiae em meio sintético foi inibido em $70 \%$ quando em presença de $4 \mathrm{~g} \mathrm{~L}^{-1}$ de $\mathrm{HMF}$, e em $89 \%$ quando em presença de $4 \mathrm{~g} \mathrm{~L}^{-1}$ de furfural. Porém, em presença de furfural $\left(2 \mathrm{~g} \mathrm{~L}^{-1}\right)$ e $\mathrm{HMF}$ $\left(2 \mathrm{~g} \mathrm{~L}^{-1}\right)$, o crescimento deste microrganismo foi inibido completamente. Estes resultados sugerem efeito sinergístico de inibição destes dois compostos.

Desta forma, acredita-se que as concentrações de furfural e HMF presentes no hidrolisado hemicelulósico de palha de arroz, não são as principais responsáveis pela inibição do metabolismo de Candida guilliermondii, para a produção de xilitol. De acordo com MCMILLAN [12], os produtos derivados da lignina (PDL) são os principais inibidores do crescimento microbiano em substratos lignocelulósicos.

\section{2 - Efeito do tratamento do hidrolisado na fer- mentação}

Geralmente, os substratos lignocelulósicos necessitam de tratamento prévio para que se tornem mais susceptíveis à ação de microrganismos [21,29]. Vários autores têm utilizado carvão ativo em processos de destoxificação de hidrolisados lignocelulósicos $[1,7,18]$ porém, a capacidade de adsorção de compostos varia com as condições de adsorção e com o tipo de carvão ativo empregado. No presente trabalho, a remoção de compostos (furfural, HMF e PDL) foi avaliada para cinco tipos de carvão ativo, com o objetivo de melhorar a bioconversão de xilose em xilitol, por Candida guilliermondii, em hidrolisado hemicelulósico de palha de arroz. As características referentes aos carvões ativos utilizados no tratamento do hidrolisado, estão apresentadas na Tabela 2.

TABELA 2. Características físicas dos carvões ativos utilizados no tratamento do hidrolisado.

\begin{tabular}{|c|c|c|c|c|}
\hline $\begin{array}{l}\text { Carvão } \\
\text { Ativo }\end{array}$ & Aspecto & $\begin{array}{l}\text { Granulometria } \\
\text { (mesh) }\end{array}$ & $\begin{array}{c}\text { Área superficial } \\
\text { especifica }{ }^{\#}\left(\mathrm{~m}^{2} \mathrm{~g}^{-1}\right)\end{array}$ & $\begin{array}{c}\text { Tamanho médio } \\
\text { das partículas * } \\
(\mathrm{mm})\end{array}$ \\
\hline A & Pó & $32 \%$ retidos em malha 325 & 860 & 0,043 \\
\hline B & Pó & $42 \%$ retidos em malha 325 & 700 & 0,043 \\
\hline C & Granulado & $20 \times 40$ & 800 & 0,601 \\
\hline D & Granulado & $8 \times 30$ & 800 & 1,452 \\
\hline$E$ & Granulado & $6 \times 10$ & 800 & 2,489 \\
\hline
\end{tabular}

"Valores determinados pelo fabricante do carvão. * O tamanho médio das partículas foi estimado de acordo com a abertura das peneiras segundo a Série Tyler de Peneiras Padrão.

As perdas dos açúcares presentes no hidrolisado, ocorridas devido ao tratamento com carvão ativo, estão apresentadas na Tabela 3. Observa-se que, independente do carvão ativo utilizado (pó ou granulado), a remoção dos açúcares presentes no hidrolisado após o 
tratamento, não foi significativa $(<5 \%)$, o que é de fundamental importância para o melhor aproveitamento da xilose no processo de obtenção de xilitol [13,15].

TABELA 3. Remoção de compostos de hidrolisado de palha de arroz concentrado, por diferentes tipos de carvão ativo.

\begin{tabular}{cccccccc}
\hline \multirow{2}{*}{ Carvão Ativo } & \multicolumn{2}{c}{ Remoção de Açúcares (\%) } & \multicolumn{3}{c}{ Remoção de Compostos Tóxicos (\%) } \\
\cline { 2 - 3 } & Glicose & Xilose & Arabinose & Furfural & HMF & PDL \\
\hline A & 2,4 & 2,3 & 1,1 & 42 & 93 & 26 \\
B & 2,6 & 2,1 & 1,0 & 50 & 90 & 31 \\
C & 1,9 & 0,1 & 0,7 & 96 & 66 & 15 \\
D & 2,2 & 1,0 & 0,4 & 54 & 39 & 12 \\
E & 2,3 & 1,3 & 2,3 & 8 & 11 & 7 \\
\hline
\end{tabular}

Na Tabela 3 encontram-se também apresentados os resultados referentes à influência do tratamento na remoção de furfural, HMF e PDL, empregando os diferentes tipos de carvão ativo. Observa-se que a remoção destes compostos variou de acordo com o tipo de carvão empregado, sendo que a máxima remoção de furfural, HMF e PDL, foi de 96\%; 93\% e 31\% para os carvões C, A e $\mathrm{B}$, respectivamente.

Para a remoção de PDL, os carvões ativos em pó mostraram-se mais eficientes que os granulados, independente da área superficial específica. A remoção destes compostos variou de $7 \%$ (carvão granulado E) a $31 \%$ (carvão em pó A), correspondendo a um aumento de $343 \%$. Dentre os carvões ativos granulados observa-se um favorecimento na remoção destes compostos com a diminuição da granulometria da partícula de carvão utilizada no tratamento. De acordo com HOW \& MORR [9] os carvões ativos granulados demoram mais para atingir o equilíbrio de adsorção que os carvões ativos pulverizados. Sendo assim, o tempo de tratamento empregado neste trabalho pode não ter sido suficiente para atingir o equilíbrio de adsorção nos carvões ativos granulados, ocorrendo maior adsorção de compostos em carvão ativo pulverizado. Além disso, segundo SWIATKOWSKI [25] os carvões ativos em pó apresentam partículas de tamanho muito pequeno (geralmente menor que $100 \mu \mathrm{m}$ de diâmetro), o que confere menor resistência na difusão das moléculas de adsorbato no adsorvente e conseqüentemente apresentam maior taxa de adsorção de compostos quando comparada aos carvões ativos granulados.

Ainda na Tabela 3 observa-se que, assim como para a remoção de PDL, os resultados referentes a remoção de HMF também mostraram maior eficiência dos carvões ativos em pó, em relação aos granulados, sendo que dentre os carvões ativos granulados, a remoção de HMF também foi favorecida com a diminuição da granulometria da partícula.

A remoção de furfural não foi muito influenciada pela granulometria dos carvões utilizados, variando independentemente do carvão ser em pó ou granulado. Neste caso, a remoção de furfural pode ter ocorrido em função de outra propriedade do carvão ativo, que não foi abordada neste estudo. Vários autores relatam que dentre as propriedades que conferem elevada capaci- dade de adsorção do carvão ativo, a presença de grupos funcionais em sua superfície (grupos carboxila, carbonila, lactonas, ácidos carboxílicos, entre outros), decorrente do processo de ativação a que o carvão foi submetido, é um dos fatores que exerce grande influência no processo de adsorção, uma vez que promove uma seletividade na remoção de compostos $[2,3,25]$.

Na Figura 1 verifica-se que o consumo de xilose variou de acordo com o carvão ativo utilizado no tratamento do hidrolisado. Os maiores consumos desta pentose foram observados em hidrolisados tratados com carvões ativos em pó, sendo que dentre estes, o hidrolisado tratado com o carvão do tipo A foi o que apresentou maior consumo de xilose, restando apenas $2,97 \mathrm{gL}^{-1}$ após 96h de fermentação. Ao final da fermentação, observase também que dentre os carvões ativos granulados, o consumo de xilose foi favorecido com a diminuição do tamanho das partículas utilizadas no tratamento do hidrolisado, como conseqüência da maior remoção de inibidores (Tabela 3).

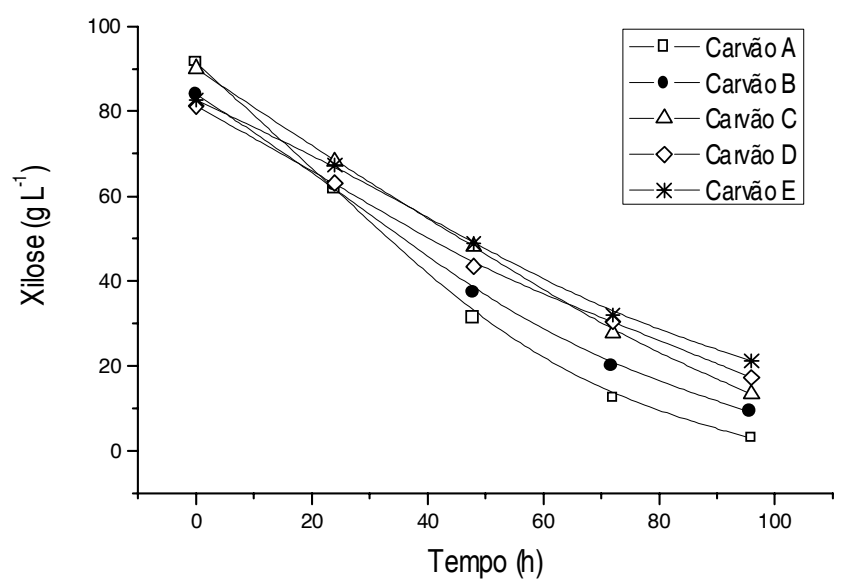

FIGURA 1. Consumo de xilose por C. guilliermondii em hidrolisado de palha de arroz tratado com diferentes tipos de carvão ativo.

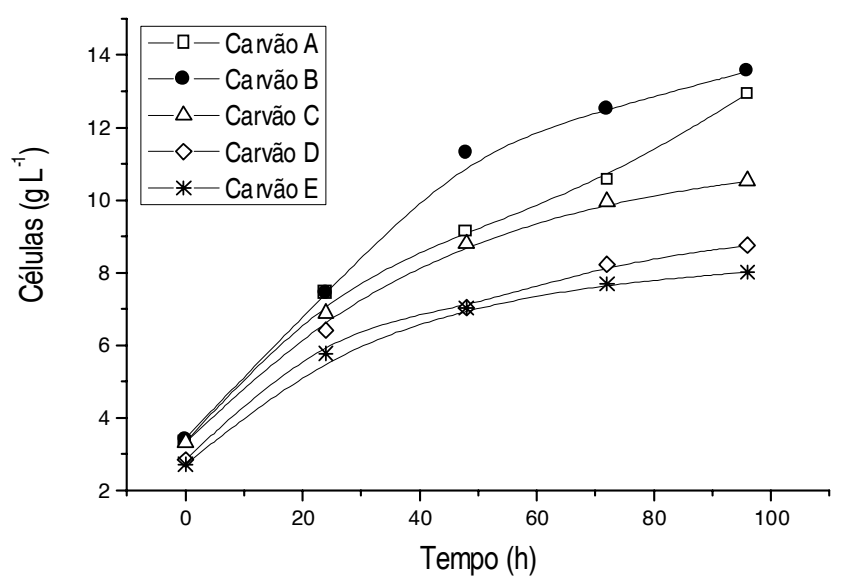

FIGURA 2. Crescimento de C. guilliermondii em hidrolisado de palha de arroz tratado com diferentes tipos de carvão ativo.

Similar ao consumo de xilose, nota-se que o crescimento celular (Figura 2) foi favorecido em hidrolisa- 
dos tratados com carvões ativos em pó. Quanto aos carvões ativos granulados, ocorreu diminuição no crescimento de forma que, quanto maior a granulometria do carvão utilizado, menor a concentração celular final, o que mostra o efeito das concentrações dos inibidores não removidos. O aumento observado no crescimento celular não refletiu no favorecimento da produção de xilitol (Figura 3), visto que para o hidrolisado onde se obteve maior concentração celular (Carvão B), não ocorreu também a maior formação do produto.

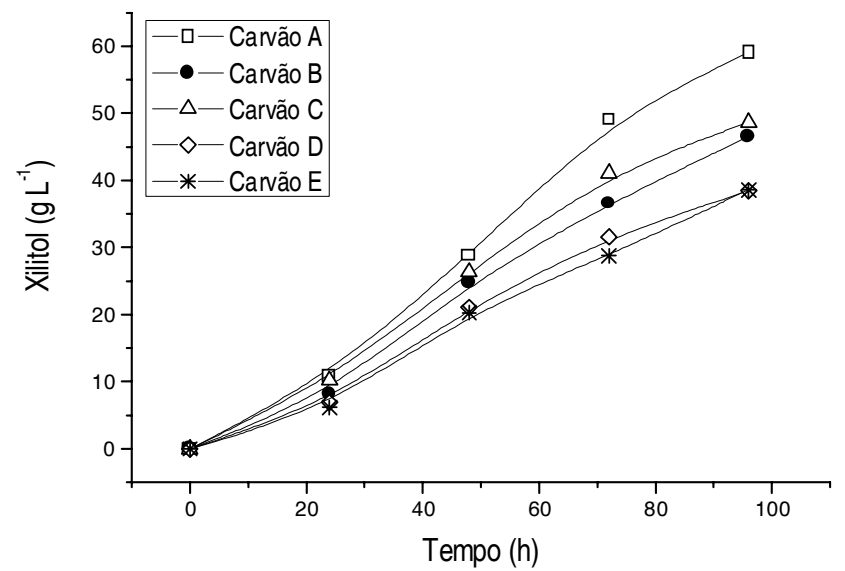

FIGURA 3. Produção de xilitol por C. guilliermondii em hidrolisado de palha de arroz tratado com diferentes tipos de carvão ativo.

Devido à adsorção de compostos ocorrer de forma seletiva para cada tipo de carvão [2,3,25], e sabendo que os produtos derivados da lignina constituem os compostos fenólicos (ácido p-hidroxibenzóico, ácido vanílico, ácido siríngico, vanilina, seringaldeído, ácido p-cumárico, ácido ferúlico, entre outros), aromáticos e aldeídos [24], os resultados obtidos nesta etapa do trabalho sugerem que os compostos removidos com o uso do carvão A provavelmente não foram exatamente os mesmos removidos com o uso do carvão $\mathrm{B}$, apesar da remoção de PDL obtida em ambos os casos ter sido muito similar. Este fato também é capaz de explicar os resultados similares obtidos na bioconversão a partir do hidrolisado tratado com os carvões granulados D e $\mathrm{E}$, uma vez que estes apresentaram diferentes desempenhos na remoção de compostos tóxicos (Tabela 3).

Vários autores têm avaliado o uso de carvão ativo na adsorção de compostos tóxicos presentes em hidrolisados lignocelulósicos [1,7,14,18]. Entretanto não há ainda um trabalho que relacione a influência da remoção de cada produto derivado da lignina, em processos de bioconversão a partir destes hidrolisados. Normalmente é reportada uma melhoria em processos de bioconversão, através da remoção geral de produtos derivados da lignina, sem que seja realizada nenhuma avaliação mais específica de quais foram os compostos realmente removidos. No presente trabalho, apesar dos carvões A e B terem removido de forma muito similar os PDL, o tratamento do hidrolisado com o carvão B promoveu meio de cultivo favorável ao aumento de massa celular, enquanto que o hidrolisado tratado com o car- vão A proporcionou meio mais favorável à bioconversão de xilose em xilitol.

Para os carvões ativos granulados, a concentração de xilitol aumentou de 38,5 para $48,6 \mathrm{~g} \mathrm{~L}^{-1}$ quando o tamanho médio das partículas do carvão foi decrescido de 1,452 para $0,601 \mathrm{~mm}$. Porém, o aumento no tamanho da partícula de carvão de $1,452 \mathrm{~mm}$ para $2,489 \mathrm{~mm}$, não interferiu na produção de xilitol, que atingiu nível da ordem de 38,5g L-1 em ambos os casos. Estes resultados sugerem que a utilização de carvões ativos de baixa granulometria no tratamento do hidrolisado, favorece a remoção de compostos que interferem na produção de xilitol.

A Figura 4 mostra os valores das produtividades volumétricas $\left(\mathrm{Q}_{\mathrm{P}}\right)$ e dos fatores de rendimento $\left(\mathrm{Y}_{\mathrm{P} / \mathrm{S}}\right)$ em função dos carvões utilizados para tratamento do hidrolisado.

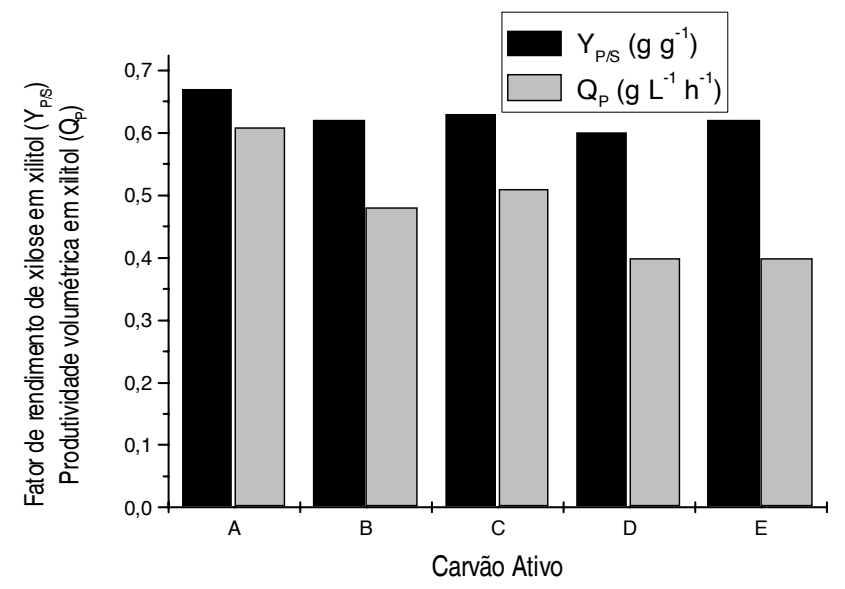

FIGURA 4. Variação de $Y_{P / S}$ e de $Q_{P}$ em fermentações de hidrolisado de palha de arroz tratado com diferentes tipos de carvão ativo.

Observa-se que os máximos valores de $\mathrm{Q}_{\mathrm{p}}\left(0,61 \mathrm{~g} \mathrm{~L}^{-1}\right.$ $\left.\mathrm{h}^{-1}\right)$ e $\mathrm{Y}_{\mathrm{P} / \mathrm{S}}\left(0,67 \mathrm{~g} \mathrm{~g}^{-1}\right)$ foram obtidos quando o hidrolisado foi tratado com o carvão ativo A. O carvão B, também em pó, apesar de ter apresentado valor de $\mathrm{Y}_{\mathrm{P} / \mathrm{S}}$ de $0,62 \mathrm{~g} \mathrm{~g}^{-1}$, próximo ao obtido com o carvão $A$, teve valor em $\mathrm{Q}_{\mathrm{P}} 27 \%$ inferior quando comparado a este carvão. Devido a ambos carvões terem o mesmo tamanho médio de partículas, esta queda na produtividade pode ser explicada novamente em relação à presença de grupos funcionais existentes na superfície dos poros do carvão. No caso do presente trabalho, o carvão ativo $\mathrm{B}$ pode ter removido certos compostos presentes no hidrolisado, que interferiram negativamente na formação do produto, diminuindo assim a produtividade do processo.

Observa-se ainda na Figura 4 que os valores de $\mathrm{Y}_{\mathrm{P} / \mathrm{S}}$ para carvões ativos granulados, não variaram significativamente, passando de 0,59 a $0,63 \mathrm{~g} \mathrm{~g}^{-1}$, e que estes valores estão próximos aos obtidos com carvões ativos em pó. Porém os niveis de $\Theta_{\mathrm{P}}$ foram bastante inferiores (da ordem de $0,40 \mathrm{~g} \mathrm{~L}^{-1} \mathrm{~h}^{-1}$ ) quando comparados aos carvões ativos em pó. Com base nos resultados obtidos, verifica-se que tanto a presença de grupos funcionais na superfície do carvão, quanto a sua granulometria, 
exercem maior influência na produtividade volumétrica $\left(\mathrm{Q}_{\mathrm{P}}\right)$ do que no fator de rendimento $\left(\mathrm{Y}_{\mathrm{P} / \mathrm{S}}\right)$ do processo.

\section{4 - CONCLUSÕES}

Os resultados experimentais obtidos neste trabalho permitem concluir que a bioconversão de xilose em xilitol por Candida guilliermondii é influenciada pelo tipo de carvão ativo utilizado no tratamento do hidrolisado hemicelulósico de palha de arroz.

Os máximos valores dos parâmetros fermentativos $\left(\mathrm{Y}_{\mathrm{P} / \mathrm{S}}=0,67 \mathrm{~g} \mathrm{~g}^{-1}\right.$ e $\left.\mathrm{Q}_{\mathrm{P}}=0,61 \mathrm{~g} \mathrm{~L}^{-1} \mathrm{~h}^{-1}\right)$, foram obtidos quando o hidrolisado foi tratado com carvão ativo em pó, que possuía partículas de tamanho médio de $0,043 \mathrm{~mm}$, baixa granulometria ( $32 \%$ retidos em malha de 325 mesh) e grande área superficial específica $\left(860 \mathrm{~m}^{2} \mathrm{~g}^{-1}\right)$, propriedades que aumentam a sua capacidade de adsorção. Estes resultados foram reduzidos em até 10\% e 34\% respectivamente, quando o hidrolisado foi tratado com carvão ativo granulado. Esta queda nos valores dos parâmetros fermentativos provavelmente ocorreu devido ao tratamento ter proporcionado menor remoção de compostos tóxicos, e interferiu principalmente na produtividade volumétrica do processo.

\section{5 - REFERÊNCIAS BIBLIOGRÁFICAS}

[1] ALVES, L.A.; FELIPE, M.G.A.; SILVA, J.B.; SILVA, S.S.; PRATA, A.M.R. Pre treatment of sugar cane bagasse hemicellulose hydrolysate for xylitol production by Candida guilliermondii. Applied Biochemistry and Biotechnology, v.70-72, p.89-98, 1998.

[2] AHMEDNA, M.; MARSHALL, W.E.; RAO, R.M. Surface properties of granular activated carbons from agricultural by-products and their effects on raw sugar decolorization. Bioresource Technology, v.71, p.103$112,2000$.

[3] AHMEDNA, M.; MARSHALL, W.E.; RAO, R.M. Production of granular activated carbons from select agricultural by-products and evaluation of their physical, chemical and adsorption properties. Bioresource Technology, v.71, p. 113-123, 2000.

[4] BARBOSA, M.F.S.; MEDEIROS, M.B.; MANCILHA, I.M.; SCHNEIDER, H.; LEE, H. Screening of yeasts for production of xylitol from d-xylose and some factors which affect xylitol yield in Candida guilliermondii. Journal of Industrial Microbiology and Biotechnology, v.3, p.241-251, 1988.

[5] CHEN, L.F.; GONG, C-S. Fermentation of sugar cane bagasse hemicellulose hydrolysate to xylitol by a hydrolysate-acclimatized yeast. Journal of Food Science, v.50, p.226-228, 1985.

[6] COUTINHO, A.R.; BARBIERI, F.C.; PAVANI, P.A. Preparação de carvões ativados a partir de fibras de celulose. $2^{\circ}$ Encontro Brasileiro Sobre Adsorção, Florianópolis, SC, p.139-144, 2000.

[7] DomingueZ, J.M.; GONG, C.S.; TSAO, G.T. Pretreatment of sugar cane bagasse hemicellulose hydrolysate for xylitol production by yeast. Applied Biochemistry and Biotechnology, v.57-58, p.49-56, 1996.

[8] FElipe, M.G.A.; MANCILHA, I.M.; VITOlO, M.; ROBERTO, I.C.; SILVA, S.S.; ROSA, S.A.M. Preparation of xylitol by fermentation of a hydrolysate of hemicellulose obtained from sugarcane bagasse. Arquivos de Biologia e Tecnologia, v.36, p.103-114, 1993.

[9] HOW, J.S.L.; MORR, C.V. Removal of phenolic compounds from soy protein extracts using activated carbon. Journal of Food Science, v.47, p.933-940, 1982.

[10] LEE, W.G.; LEE, J.S.; SHIN, C.S.; PARK, S.C.; CHANG, H.N.; CHANG, Y.K. Ethanol production using concentrated oak wood hydrolysates and methods to detoxify. Applied Biochemistry and Biotechnology, v.77-79, p.547-559, 1999.

[11] MATTILA, P.T.; KNUUTTILA, M.L.E.; SVANBERG, M.J. Dietary xylitol supplementation prevents osteoporotic changes in streptozotocin - diabetic rats. Metabolism, v.47, p. 578-583, 1998.

[12] McMillan, J.D. Conversion of hemicellulose hydrolyzates to ethanol. In: HIMMEL, M.E.; BAKER, J.O.; OVEREND, R.P. Enzymatic Conversion of Biomass for Fuels Production. Washington, 1994. Cap. 21, p. 411-437.

[13] MEYRIAL, V.; DElgenes, J.P.; MOllettA, R.; NAVARRO, J.M. Xylitol production from D-xylose by Candida guilliermondii: Fermentation Behaviour. Biotechnology Letters, v.13, p.281-286, 1991.

[14] MUSSATTO, S.I.; ROBERTO, I.C. Hydrolysate detoxification with activated charcoal for xylitol production by Candida guilliermondii. Biotechnology Letters, v.23, p.1681-1684, 2001.

[15] NOLlEAU, V.; PREZIOSI-BELlOY, L.; DELGENES, J.P.; DELGENES, J.M. Xylitol production from xylose by two yeast strains: sugar tolerance. Current Microbiology, v.27, p.191-197, 1993.

[16] OLSSON, L.; HAHN-HÄGERDAL, B. Fermentation of lignocellulosic hydrolysates for ethanol production. Enzyme and Microbial Technology, v.18, p.312-331, 1996.

[17] PARAJÓ, J.C.; DOMINGUEZ, H.; DOMINGUEZ, J.M. Production of xylitol from concentrated wood hydrolysates by Debaryomyces hansenii: effect of the initial cell concentration. Biotechnology Letters, v.18, p.593-598, 1996.

[18] PARAJÓ, J.C.; DOMINGUEZ, H.; DOMINGUEZ, J.M. Improved xylitol production with Debaryomyces hansenii y-7426 from raw or detoxified wood hydrolysates. Enzyme and Microbial Technology, v.21, p.18-24, 1997.

[19] PENDYAL, B.; JOHNS, M.M.; MARSHALL, W.E. AHMEDNA, M.; RAO, R.M. Removal of sugar colorants by granular activated carbons made from binders and agricultural by-products. Technology,v.69, p. 45-51, 1999.

[20] PEPPER, T.; OLINGER, P.M. Xylitol in sugar-free confections. Food Technology, v.42, p.98-106, 1988.

[21] ROBERTO, I.C.; FELIPE, M.G.A.; LACIS, L.C.; SILVA, S.S.; MANCILHA, I.M. Utilization of sugarcane bagasse hemicellulosic hydrolysate by Candida guilliermondii for xylitol production. Bioresource Technology, v.36, p.271-275, 1991.

[22] ROBERTO, I.C.; LACIS, L.C.; BARBOSA, M.F.S.; MANCILHA, I.M. Utilization of sugarcane bagasse hemicellulosic hydrolysate by Pichia stipitis, for the production of ethanol. Process Biochemistry, v.26, p.15-21, 1991.

[23] SANCHEZ, Z.B.; BAUTISTA, J. Effects of furfural and 5 -hydroxymethylfurfural on the fermentation of 
Saccharomyces cerevisiae and biomass production from Candida guilliermondii. Enzyme and Microbial Technology, v.10, p.315-318, 1988.

[24] SUN, R.; TOMKINSON, J.; MAO F.C.; SUN, X.F. Physicochemical characterization of lignins from rice straw by hydrogen peroxide treatment. Journal of Applied Polymer Science, v.79, p.719-732, 2001.

[25] SWIATKOWSKI, A. Industrial carbon adsorbents. In: DABROWSKI, A. Adsorption and its Applications in Industry and Environmental Protection: Studies in Surface Science and Catalysis. Poland, 1998. p. 6993.

[26] TAHERZADEH, M.J.; GUSTAFSSON, L.; NIKLASSON, C.; LIDÉN, G. Physiological effects of 5hydroxymethylfurfural on Saccharomyces cerevisiae. Applied Microbiology and Biotechnology, v.53, p.701-708, 2000.

[27] TALCOTT, S.T.; HOWARD, L.R. Phenolic Autoxidation is Responsible for Color Degradation in Processed
Carrot Puree. Journal of Agricultural Food Chemistry, v.47, p.2109-2115, 1999.

[28] UHARI, M.; KONTIOKARI, T.; NIEMELA, M. A novel use of xylitol sugar in preventing acute otitis media. Pediatrics, v.102, p.879-884, Part1, 1998.

[29] WINKELHAUSEN, E.; KUZMANOVA, S. Microbial conversion of D-xylose to xylitol. Journal of Fermentation and Bioengineering,, v.86, p.1-14, 1998.

[30] WU, F.C.; TSENG, R.L.; JUANG, R.S. Adsorption of dyes and phenols from water on the activated carbons prepared from corncob wastes. Environmental Technology, v.22, p.205-213, 2001.

\section{6 - AGRADECIMENTOS}

Os autores agradecem à FAPESP e ao CNPq, pelo apoio financeiro concedido para a execução deste trabalho. 